\title{
Essential and dispensable roles of ATR in cell cycle arrest and genome maintenance
}

\author{
Eric J. Brown ${ }^{1}$ and David Baltimore ${ }^{2}$ \\ California Institute of Technology, Pasadena, California 91125, USA
}

\begin{abstract}
A Cre/lox-conditional mouse line was generated to evaluate the role of ATR in checkpoint responses to ionizing radiation (IR) and stalled DNA replication. We demonstrate that after IR treatment, ATR and ATM each contribute to early delay in M-phase entry but that ATR regulates a majority of the late phase (2-9 h post-IR). Double deletion of $A T R$ and $A T M$ eliminates nearly all IR-induced delay, indicating that ATR and ATM cooperate in the IR-induced G2/M-phase checkpoint. In contrast to the IR-induced checkpoint, checkpoint delay in response to stalled DNA replication is intact in $A T R$ knockout cells and $A T R / A T M$ and $A T R / p 53$ double-knockout cells. The DNA replication checkpoint remains intact in $A T R$ knockout cells even though the checkpoint-stimulated inhibitory phosphorylation of Cdc2 on T14/Y15 and activating phosphorylation of the Chk1 kinase no longer occur. Thus, incomplete DNA replication in mammalian cells can prevent M-phase entry independently of ATR and inhibitory phosphorylation of Cdc2. When DNA replication inhibitors are removed, ATR knockout cells proceed to mitosis but do so with chromosome breaks, indicating that ATR provides a key genome maintenance function in $\mathrm{S}$ phase.
\end{abstract}

[Keywords: ATR; ATM; checkpoints; Chk1; Cdc2; chromosome breaks]

Received December 13, 2002; revised version accepted January 16, 2003.

DNA damage checkpoints are feedback mechanisms that sense the physical state of the genome. Should the integrity of the genome be compromised, checkpoint proteins signal these events and thereby prevent initiation of the next cell cycle phase. To do so, DNA damage checkpoint proteins interface with and inhibit the Cdk/ cyclin machinery, the normal function of which is to activate and coordinate genome duplication and partitioning (Zhou and Elledge 2000; Nyberg et al. 2002). In mammalian cells, two important regulators of DNA damage checkpoints are ATR and ATM, unconventional protein kinases that phosphorylate and activate signal transduction pathways that ultimately interface with the Cdk/Cyclin machinery.

$A T R$ and ATM are structurally and functionally similar to two checkpoint genes in yeast, MEC1 (Saccharomyces cerevisiae) and RAD3 (Schizosaccharomyces pombe), which regulate analogous pathways to control the cell cycle machinery. However, whereas Mec1 and Rad3 regulate nearly all responses to damage or inhibited DNA replication in their respective organisms, checkpoint regulation in mammals appears to be unevenly divided between ATR and ATM. Based mostly on studies

Corresponding authors.

${ }^{1}$ E-MAIL ejbrown@caltech.edu; FAX (626) 585-9495.

2E-MAIL baltimo@caltech.edu; FAX (626) 585-9495.

Article published online ahead of print. Article and publication date are at http://www.genesdev.org/cgi/doi/10.1101/gad.1067403. of signal transduction pathways activated upon DNA damage and stalled DNA replication, ATR has been shown to regulate responses to a broad range of damage, including pyrimidine dimers, stalled replication, and double-stand breaks (DSBs). ATM, on the other hand, seems to be more specifically involved in responses to DSBs (Zhou and Elledge 2000; Nyberg et al. 2002). For example, through dominant-negative overexpression studies, ATR has been implicated in the regulation of IRand ultraviolet light (UV)-induced phosphorylation of p53 on serine 15 (S15) and UV- and aphidicolin-induced phosphorylation of the Chk1 protein kinase on S345 (Tibbetts et al. 1999; Liu et al. 2000; Zhao and PiwnicaWorms 2001). In addition, a recently generated Cre/loxconditional cell line has been used to demonstrate that ATR is required for phosphorylation of $\operatorname{Rad} 17$ in response to UV (Zou et al. 2002). In contrast to ATR deficiency, ATM loss predominantly affects responses to DSBs, such as IR-induced phosphorylation of the Chk2 protein kinase, S15 p53, NBS1, and other proteins (Matsuoka et al. 1998; Kastan and Lim 2000).

Although the effects of ATR dominant-negative overexpression and ATM loss on signaling pathways have led to a relatively simple model of checkpoint regulation, the comparative requirements for ATR and ATM in ultimately preventing cell cycle progression has remained less clear. For example, although both ATR and ATM have each been shown to play a role in preventing mitotic entry in response to IR /Cliby et al. 1998; Cortez et 
al. 2001; Xu et al. 2002), it is unknown whether ATR and ATM regulate this response in an additive or epistatic manner or whether one protein may play a more important role than the other. Moreover, ATR's involvement in preventing mitotic entry in response to stalled DNA replication has remained particularly obscure. Although in vitro experiments using Xenopus extracts have shown an important role for ATR in preventing nuclear envelope breakdown upon inhibition of DNA synthesis (Guo et al. 2000; Hekmat-Nejad et al. 2000), systems using dominant-negative ATR overexpression have led to contradictory results in mammalian cells (Cliby et al. 1998; Nghiem et al. 2001, 2002). At the present time, it is not clear whether these contradictory results may be caused by differences in the degree of dominant-negative overexpression or in the undefined genetic background of the tumor cell lines used. Adding to the complexity of ATR's role in the DNA replication checkpoint are recent studies in yeast that imply a role for ATR in preventing DSBs in response to stalled replication (Lopes et al. 2001; Cha and Kleckner 2002). Because one would then expect stalled replication forks to be converted into DSBs in the absence of ATR, it is difficult to predict if the DNA replication checkpoint would be eliminated by ATR deficiency. Loss of genome stability in ATR mutants could contribute to cell cycle inhibition upon replication arrest and do so in an ATR-independent manner.

To compare the role of ATR and ATM in cell cycle checkpoint control, a mouse line expressing a Cre/loxconditional allele of ATR was generated. This system allowed comparison of checkpoint requirements for ATR and ATM in cells that are untransformed and of an isogenic background. Using $A T R^{\text {flox } /-}, A T M^{-/-}$, and $A T R^{\text {flox } /-} A T M^{-/-}$murine embryonic fibroblasts (MEFs), we have assessed the roles of ATR and ATM in checkpoint responses to IR and stalled DNA replication. In response to IR, we show that ATR contributes to preventing mitotic entry in a time-dependent manner, regulating the late phase of the response and cooperating with ATM in the early phase. Because little or no delay is observed in IR-treated ATR/ATM double knockouts, these results indicate that together these genes regulate a majority of the response to IR that inhibits mitotic entry. However, in contrast to IR-induced checkpoint responses, we have found that delayed mitotic entry in response to stalled DNA replication occurs even when ATR and ATM are deleted. This delay is evident despite the fact that ATR is required both for phosphorylation of Chk1 and for inhibitory phosphorylation of Cdc2 in response to either IR or stalled replication. Furthermore, although we find that DSBs are, indeed, generated specifically in ATR knockout cells upon DNA replication stalling, these breaks themselves do not prevent mitotic entry once DNA replication inhibitors are removed. These data show that both IR- and aphidicolin-induced checkpoints use ATR for signaling events that ultimately lead to inhibitory phosphorylation of Cdc2; however, in response to stalled replication, at least one additional mechanism must be at work in preventing mitotic entry.

\section{Results}

Generation of a lox-conditional allele of ATR

Previous ATR knockout studies demonstrated that ATR is required for genomic stability in the early embryo and that its loss leads to early embryonic lethality (Brown and Baltimore 2000). To further explore the cellular functions of ATR in cell cycle regulation and genome maintenance, a Cre/lox-conditional allele of ATR was generated in mice. Murine genomic clones of the $3^{\prime}$ end of the ATR locus were mapped and sequenced to reveal two exons encoding essential components of the ATR kinase domain (KD1 and KD2), including the catalytic residues conserved in human ATR, D2475 and D2494 (Fig. 1A). lox sites were placed on each side of a $1.2-\mathrm{kb}$ region that includes KD1 and KD2 in the ES cell targeting vector shown (Fig. 1A). Upon lox recombination of this allele, KD1 and KD2 deletion and a subsequent frameshift in $3^{\prime}$ exons is predicted, thereby truncating the ATR gene product 5' of KD1 (amino acid 2398). Following transfection and selection of D3 ES cells, recombination into the ATR locus was confirmed by Southern blot hybridization to two probes generated from sequences $5^{\prime}$ and $3^{\prime}$ of the targeted region; detection of a 22.5-kb BamHI-KpnI (5'-probe) and an 11.5-kb HindIII $\left(3^{\prime}\right.$-probe) band indicated appropriate recombination (Fig. $1 \mathrm{~A}, \mathrm{~B}$, Recombined). Note that when recombinatorial crossover occurs within the $1.2-\mathrm{kb} \mathrm{KD} 1 / \mathrm{KD} 2$ region rather than outside of it, then 19.5-kb BamHI-KpnI and 18-kb HindIII bands are generated (Fig. 1A,B, Internal rec.). Appropriately targeted ES cells were then transfected with a vector expressing FLP recombinase (Buchholz et al. 1998) to remove the selection cassette by frt recombination (Fig. 1A). Removal of the selection cassette resulted in an allele in which KD1 and KD2 are flanked by lox sites and only a single frt site remains (Fig. 1A). This final configuration was detected by a $4.5-\mathrm{kb}$ decrease in the BamHI-KpnI fragment length to $18 \mathrm{~kb}$ (Fig. 1A,B, Conditional). An ES cell clone with this configuration was subsequently used to generate chimeric mice, 3 in 10 of which transmitted the lox-conditional ATR allele through the germ line. In the studies described below, this conditional allele is abbreviated as $A T R^{\text {flox }}$, and the following lox recombination is referred to as $A T R^{\Delta}$.

\section{$\mathrm{ATR}^{\Delta /-}$ cells divide normally 1-2 times after ATR loss} and then exit the cell cycle

To study the effect of ATR loss in primary cell proliferation, embryonic day 14.5 (E14.5) embryos isolated from parental crosses of $A T R^{\text {flox/+ }}$ with $A T R^{+/-}$(Brown and Baltimore 2000) mice were used to generate wild-type, $A T R^{+/-}, A T R^{\text {flox } /+}$, and $A T R^{\text {flox } /-}$ murine embryonic fibroblasts (MEFs). Previously, we have shown that ATR is required for proliferation of early embryonic cells in culture (Brown and Baltimore 2000). To test if E14.5 MEFs also require ATR, the $A T R^{\text {flox/- }}$ and control cells described above were infected with a lentivirus that ex- 


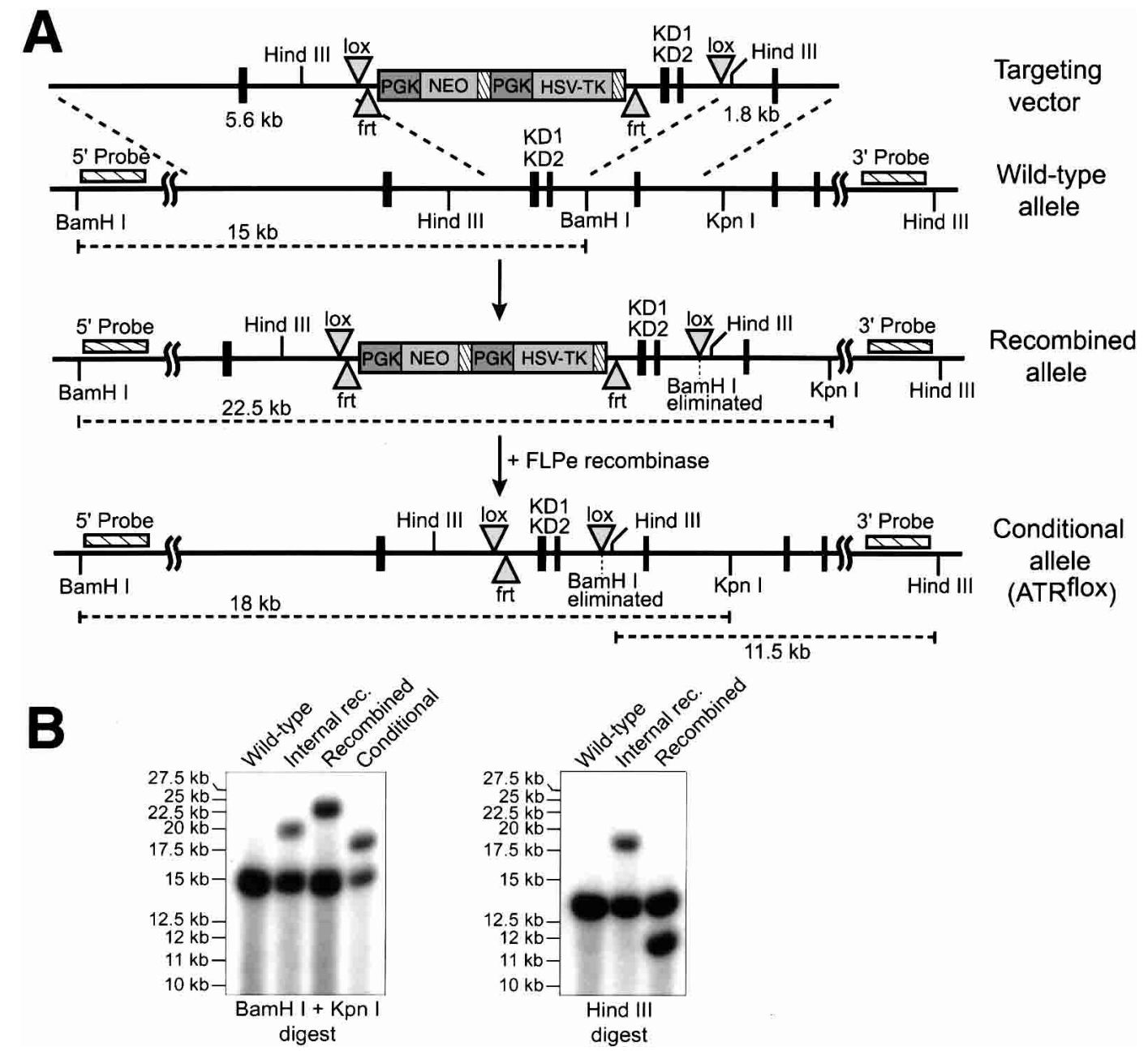

Figure 1. Generation of a floxed conditional allele of $A T R\left(A T R^{\text {flox }}\right)$. (A) Schematic representations of the targeting vector, wild-type $A T R$ locus, recombined locus, and the final conditional allele of $A T R$ ( $\left.A T R^{\text {flox }}\right)$ are shown. Following confirmation by Southern blot, the ES cells with a recombined ATR allele were transfected with the pCAGGS-FLPe expression vector (Buchholz et al. 1998) to remove the selection cassette. Removal of the selection cassette results in the lox-conditional (ATR $\left.{ }^{\text {flox }}\right)$ allele shown. $(B)$ Confirmation of the $A T R^{\text {flox }}$ allele by Southern blot. DNA prepared from ES cell clones was digested with BamHI + KpnI or HindIII alone and Southernblotted for hybridization with the $5^{\prime}$ and $3^{\prime}$ probes indicated in $A$, respectively. DNA fragments representing wild-type, internally recombined, recombined, and $A T R^{\text {flox }}$ alleles are discussed in the text and indicated in $A$.

presses EGFP fused to a nuclear-localized form of Cre recombinase (NLS-Cre). Cells initially expressing the EGFP-Cre fusion protein were then followed for continued representation in proliferating cultures by flow cytometry over the course of $8 \mathrm{~d}$ (Fig. 2A). A selective loss of $A T R^{\text {flox } /-}$ cells expressing EGFP-Cre was observed 5 to $8 \mathrm{~d}$ after infection. However, because lox recombination was typically complete within $36 \mathrm{~h}$ of Cre expression (data not shown), these results indicated that ATR-depleted cells may divide normally soon after ATR depletion, but ultimately exit the cell cycle.

To test this possibility, $A T R^{\text {flox } /-}$ and wild-type cells were synchronized in G0 by culturing in reduced serum $(0.5 \%$ FBS $)$ for $1 \mathrm{~d}$ and were then infected with Cre-expressing lentivirus at near saturation levels $(>90 \%$ infected). These wild-type and $A T R^{\Delta /-}$ cultures were then maintained in reduced serum for an additional $2 \mathrm{~d}$ and subsequently stimulated with $10 \%$ FBS for 18 to $24 \mathrm{~h}$.
Whereas ATR was depleted within $60 \mathrm{~h}$ of lenti-Cre infection (Fig. 2B), little difference was observed in the ability of lenti-Cre-infected $A T R^{\text {flox/- }}$ and wild-type cells to enter S and G2/M phase within $24 \mathrm{~h}$ of FBS stimulation (66-72 h after lenti-Cre infection; Fig. 2C). However, $2-6 \mathrm{~d}$ of continued culture in growth media resulted in a loss of proliferation accompanied by the appearance of large flattened cells (Fig. 2D) and a small increase in Annexin V staining (less than twofold over wild type). Thus, although ATR is required for long-term proliferation, ATR-depleted cells exhibit a relatively normal cell division cycle soon after ATR loss.

\section{ATR and ATM cooperate in preventing mitotic entry in response to $I R$}

The synchronization, infection, and serum-restimulation procedure described above and in Figure 2B and C, 
Figure 2. $A T R^{\Delta /-}$ cells divide and then exit the cell cycle. (A) Asychronously expanding $A T R^{\text {flox/- }}$ MEFs expressing EGFPCre are selectively lost from culture. The cells that continue to express EGFP-Cre over the course of $8 \mathrm{~d}$ of growth were quantitated as a percentage of their initial representation $1 \mathrm{~d}$ after infection with lentiEGFP-Cre. - wild type; $\bullet, A T R^{+/-}$; $A T R^{\text {flox } /+} ; \boldsymbol{\Lambda}, A T R^{\text {flox } /-}$. (B) Western blot quantitation of ATR protein levels in $A T R^{\text {flox } /-}$ and $A T R^{+/-}$MEFs $60 \mathrm{~h}$ after NLS-Cre expression (lenti-Cre). (C) Cell cycle analysis of lenti-Cre-infected wildtype and $A T R^{\text {flox/- }}$ MEFs. DNA content was determined by propidium iodide staining and flow cytometric analysis. $(D)$ Exit of $A T R^{\Delta /-}$ cells from the cell cycle. Cells treated as in $C$ are shown after 1 and $6 \mathrm{~d}$ of FBS stimulation. Cells were split 1:4 at day 3 .
A
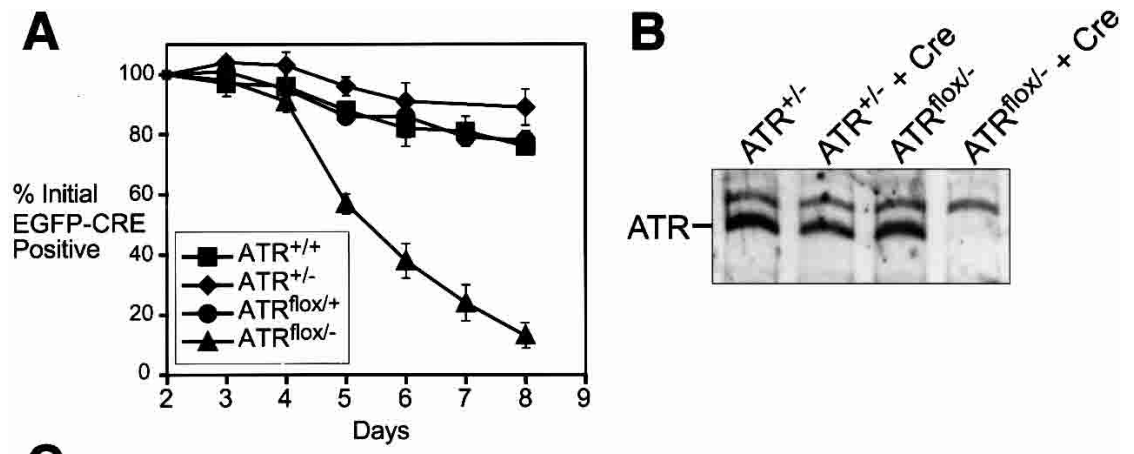

D

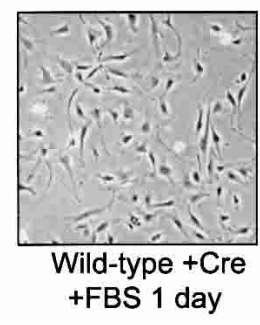

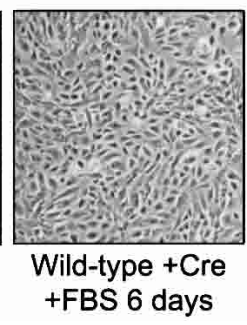

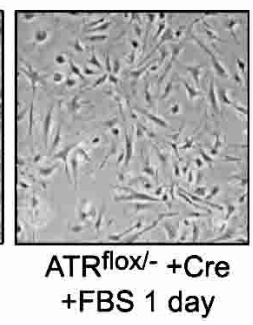

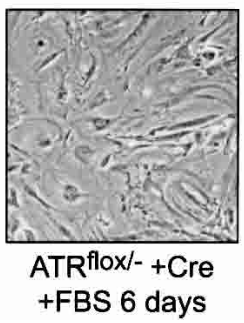

provided a system to analyze ATR's role in cell cycle checkpoint regulation. Because previous studies have attributed IR-induced checkpoint responses to both ATR and ATM (Cliby et al. 1998; Cortez et al. 2001; Xu et al. 2002), we first wished to clarify the roles of ATR and ATM in this response using a defined genetic background and in the context of a single cell type (MEFs). To compare the roles of ATR and ATM in this checkpoint response, serum-starved wild-type, $A T R^{\text {flox } /-}$, and $A T M^{-/-}$MEFs were infected with Cre-expressing lentivirus and restimulated with serum as described above (Fig. 2B,C). After $17 \mathrm{~h}$ of FBS stimulation, $A T R^{\Delta /-}$ and control cells began to enter mitosis (Fig. 3B). Cells were exposed to $20 \mathrm{~Gy}$ of $\gamma$-radiation at this time and were subsequently treated with nocodazole $(0.5 \mu \mathrm{M})$ for $5 \mathrm{~h}$ to allow accumulation in mitosis. Entry into mitosis was then analyzed in two ways. In the first, mitotic spreads were prepared, and the ratio of mitotic and interphase cells was counted (Fig. 3A, panel 1). In the second, cells were stained for phosphohistone $\mathrm{H} 3$, a mitotic marker, and analyzed by flow cytometry (Fig. 3A, panel 2). Using either form of quantitation, these data demonstrated that ATR plays an important role in preventing cells from entering mitosis after IR exposure and by this analysis appeared to play a more important role than ATM (Fig. 3A). Using a 10-Gy dose, a similar level of ATR dependence for checkpoint delay was observed (data not shown). It is important to point out that nocodazole "pile up" nullifies temporal differences in mitotic entry by collecting mitotic cells over a set course of time, in this case $5 \mathrm{~h}$. Because complete loss of checkpoint function was not observed in either single knockout, we thought these genes might cooperate in the IR response, perhaps in a temporal manner. Evidence in support of ATM contributing to early delays in M phase entry in response to IR has been reported (Xu et al. 2002).

To test if ATR plays a time-dependent role in IR-induced responses, ATR-depleted and wild-type MEFs were assayed for the rate of entry into mitosis after exposure to IR at $17 \mathrm{~h}$ of FBS stimulation (Fig. 3B). Noco- 

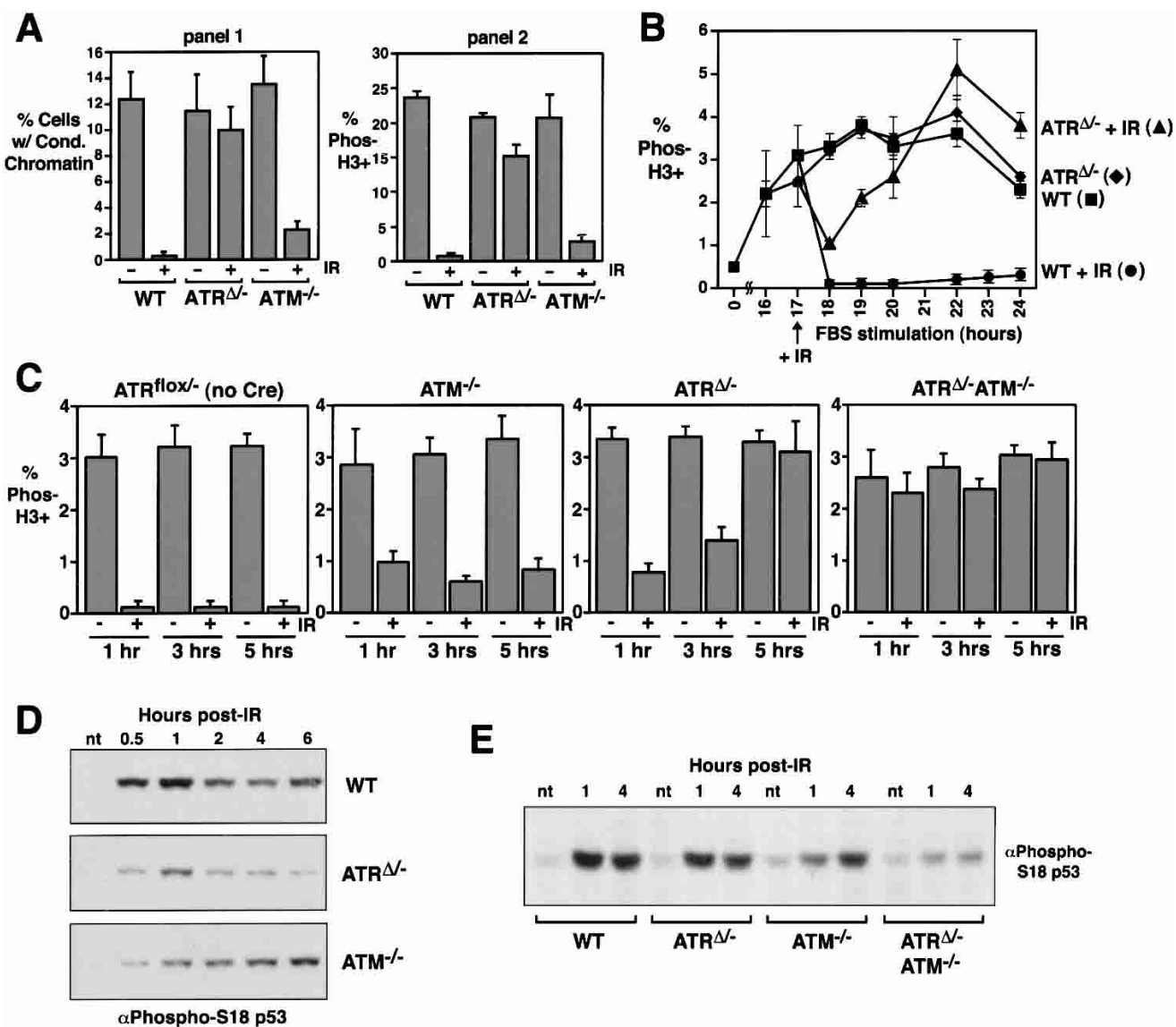

$\mathbf{E}$

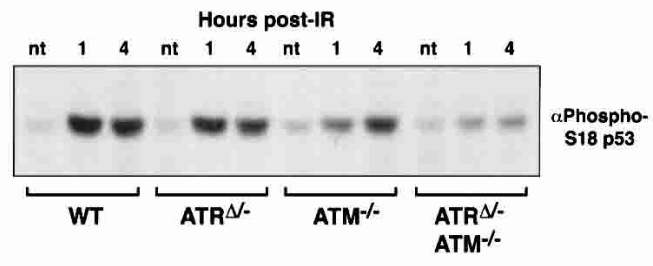

Figure 3. ATR and ATM cooperate in checkpoint responses to $\gamma$-irradiation. $(A)$ Serum-deprived and lenti-Cre-infected wild-type, $A T R^{\text {flox } /-}$, and $A T M^{-1-}$ MEFs were $\gamma$-irradiated $(20 \mathrm{~Gy})$ after $17 \mathrm{~h}$ of FBS stimulation and then treated with $0.5 \mu \mathrm{M}$ nocodazole for $5 \mathrm{~h}$ (corresponding to 18-23 h of FBS stimulation). The percentage of cells exhibiting chromosome condensation (panel 1) and phosphorylated histone H3 (panel 2) were quantitated by chromosome spread preparation and immunostaining, respectively. Differences between the total percent of cells with condensed chromatin (panel 1) versus phosphohistone $\mathrm{H} 3$ staining (panel 2) is consistent with the phosphorylation of histone $\mathrm{H} 3$ occurring prior to condensation and remaining phosphorylated throughout M phase. $(B)$ ATR is required for late-phase mitotic delay in response to IR. Entry into mitosis (without nocodazole treatment) was quantitated by phosphohistone H3 staining before and after treatment with $20 \mathrm{~Gy}$ of $\gamma$-radiation at $17 \mathrm{~h}$ of FBS stimulation. $\mathbf{\square}$, wild-type; $\boldsymbol{\bullet}, A^{-} R^{\Delta /-}$; $\mathbf{0}$, wild-type + IR; $\boldsymbol{\Delta}, A T R^{\Delta /-}+$ IR. (C) ATR and ATM cooperate in the cell cycle delay elicited by IR. Mitotic entry was assessed after IR exposure as in $B$ to compare mitotic entry of $A T R^{\text {flox } /-}$ (no lenti-Cre infection), $A T M^{-1-}$, and lenti-Cre-infected $A T R^{\text {flox } /-}$ and $A T R^{\text {flox } /-} A T M^{-/-}$ $\left(A T R^{\Delta /-}\right.$ and $\left.A T R^{\Delta /-} A T M^{-/-}\right)$MEFs. $A T R^{\text {flox } /-}$ and $A T R^{\text {flox } /-} A T M^{-/-}$MEFs were derived from embryonic littermates. (D) ATR and ATM cooperate in p53 S18 phosphorylation. Lysates generated from lenti-Cre-infected wild-type, $A T R^{\text {flox } /-}$, and $A T M^{-/-}$cells at various times after IR treatment were Western-blotted and detected with a phospho-specific antibody to phospho-S18 p53. (E) Cells treated as described in $C$ were analyzed for p53 S18 phosphorylation by Western blot detection as described in $D$. Error bars represent the standard deviation (S.D.) from the mean of values obtained in these experiments. nt, not treated with IR.

dazole treatment was not used in these experiments; therefore, the percentage of mitotic cells represents normal entry into mitosis following FBS stimulation. As shown in Figure 3B, ATR is required for the late phase of the response, beginning $\sim 3-4 \mathrm{~h}$ after IR treatment, but it is less important for the checkpoint response soon after IR exposure (e.g., $1 \mathrm{~h}$ after IR). To test if ATM plays a role in the early phase of the response in the context of this system, the $A T R^{\text {flox }}$ allele was bred into an $A T M$ knockout background, and the same assay was performed (Fig. 3C). Whereas ATR and ATM individually played only partial and time-dependent roles in this checkpoint response, ATR/ATM double-knockout cells entered mitosis similarly to unirradiated cells. Because significant de- lay was not observed either early or late in the response, these data indicate that a majority, if not all, of IR-induced cell cycle delay is governed cooperatively by ATR and ATM (Fig. 3C).

To further analyze the time-dependent requirement for ATR and ATM, p53 S18 phosphorylation was analyzed for its kinetic dependence on ATR and ATM. S18 phosphorylation has been shown to be important for p53's checkpoint activity in the mouse (Chao et al. 2000), and phosphorylation of the sequence-context equivalent in human cells (S15) has previously been suggested to be ATR-dependent in the late phase based on dominant-negative ATR overexpression (Tibbetts et al. 1999). Figure 3D and E shows that consistent with the 
assay for mitotic entry, p53 phosphorylation appears to require both ATR and ATM in a time-dependent manner and that both ATR and ATM must be deleted to prevent phosphorylation over the long term.

In response to stalled DNA replication, cell cycle delay is intact in ATR and ATR/ATM

double-knockout cells

After assessing ATR's role in IR-induced checkpoint regulation, we set out to determine if ATR was required in a similar manner for other checkpoint responses, such as the cell cycle delay resulting from stalled DNA replication. Three assays were used to quantitate mitotic entry: histone $\mathrm{H} 3$ phosphorylation, $\mathrm{Cdc} 2 / \mathrm{Cyclin} \mathrm{B} 1$ activation, and chromosome condensation. First, in a timecourse assay similar to that used for IR-induced delay, wild-type and $A T R^{\Delta /-}$ cells were treated or left untreated with aphidicolin $(5 \mu M)$ as cells began to pass into $S$ phase, $15 \mathrm{~h}$ after FBS stimulation; cells subsequently entering mitosis were quantitated by phosphohistone $\mathrm{H} 3$ staining. Surprisingly, aphidicolin treatment potently inhibited both wild-type and $A T R^{\Delta /-}$ cells from entering mitosis (Fig. 4A). To further examine this inhibition, cyclin B1-associated H1 kinase activity was assayed 3-9 h after aphidicolin or IR treatment (Fig. 4B). Consistent with the loss of IR-induced mitotic delay in $A T R^{\Delta /-}$ cells (Fig. 3), cyclin B1-associated H1 kinase activity was not significantly inhibited by IR exposure (Fig. 4); however, H1 kinase activity was inhibited by aphidicolin treatment of either wild-type or $A T R^{\Delta /-}$ cells (Fig. 4). Finally, ATR's role in the DNA replication checkpoint was examined by quantitating the percentage of cells with condensed chromatin (Fig. 4C). These results also showed that ATR is dispensable for preventing mitotic entry in response to stalled DNA replication (Fig. 4C).

Because ATM cooperates with ATR in IR-induced responses (Fig. 3), we wondered if ATM may be compensating in the DNA replication checkpoint for ATR's loss. It was also possible that p53 may cooperate with ATR in this checkpoint, as suggested by ATR dominant-negative studies (Nghiem et al. 2002). To test these possibilities, the checkpoint function of $A T R^{\Delta /-}$ cells was compared with that of $A T R^{\Delta /-} A T M^{-/-}$and $A T R^{\Delta /-} p 53^{-/-}$doubleknockout MEFs (Fig. 4D). In each case, the DNA replication checkpoint function remained intact. These results demonstrate that ATR and ATM are dispensable for preventing mitotic entry upon stalled DNA replication.

\section{Roles of ATR and ATM in Chk1 and Chk2 regulation}

The ability of ATR knockout cells to arrest normally in the face of stalled DNA replication is surprising given numerous reports of ATR's role in regulating downstream signaling events, such as the phosphorylation of Chk1 (Guo et al. 2000; Hekmat-Nejad et al. 2000; Liu et al. 2000; Zhao and Piwnica-Worms 2001). To confirm ATR's role in regulating downstream signaling events using the ATR knockout system described herein, wildtype and $A T R^{\Delta /-}$ cells were treated with aphidicolin $(5$ $\mu \mathrm{M}$ ) or exposed to $20 \mathrm{~Gy}$ of $\gamma$-radiation, and cells were harvested at various times posttreatment for Western blot analysis (Fig. 5A). Chk1 phosphorylation was then evaluated by both detection with phospho-specific antibodies to serine 345 (Liu et al. 2000) and by mobility shift (Sanchez et al. 1997; Kumagai et al. 1998). In wild-type cells, Chk1 phosphorylation was strongly increased in response to aphidicolin treatment and moderately to weakly increased following exposure to IR. Note that multiple forms of decreased electrophoretic mobility were detected, similar to those observed for Xenopus Chk1 upon in vitro phosphorylation (Kumagai et al. 1998; Guo et al. 2000; Hekmat-Nejad et al. 2000). In $A T R^{\Delta /-}$ cells, both aphidicolin- and IR-induced phosphorylation of Chk1 was inhibited, confirming an important role for ATR in regulating Chk1.

We then analyzed phosphorylation of Chk2 to determine its requirements for ATR and ATM in response to stalled replication. Whereas ATR deletion had no inhibitory effect on either the potent IR-induced phosphorylation of Chk2 or the mild phosphorylation resulting from aphidicolin treatment (Fig. 5B), ATM deletion prevented most of the mild aphidicolin-induced phosphorylation (Fig. 5B), consistent with previous studies using IR (Matsuoka et al. 1998). Therefore, because the DNA replication checkpoint remains intact even in $A T R^{\Delta /-} A T M^{-/-}$ cells (Fig. 4D), mitotic delay in response to stalled replication cannot be solely through Chk2 phosphorylation. It is also important to point out that the late phase of IR-induced Chk2 phosphorylation in $A T R^{\Delta /-}$ cells (Fig. $5 \mathrm{~B}$ ) is not sufficient to prevent mitotic entry (Fig. 3B), indicating that moderate to high levels of Chk2 phosphorylation are incapable of generating delay on their own. Thus, in regard to the checkpoint response to stalled replication, our studies indicate that the ATRChk1 and ATM-Chk2 pathways are dispensable for the mitotic delay induced by DNA replication inhibitors.

\section{Checkpoint-induced inhibitory phosphorylation of Cdc2 on T14 and Y15 is ATR-dependent}

Although ATR and ATM are required for cell cycle delay in response to IR, the results described above indicate that ATR and ATM and the activation of Chk1 and Chk2 are dispensable for the ultimate cell cycle arrest that occurs in response to stalled DNA replication. Chk 1 and Chk2 are upstream regulators of several signaling pathways that ultimately control phosphorylation of Cdc2 on threonine 14 (T14) and tyrosine 15 (Y15), thereby inhibiting Cdc2's catalytic activity (Norbury and Nurse 1992; Nyberg et al. 2002). Given that inhibitory phosphorylation of Cdc2 on T14 and Y15 is an important mode of cell cycle regulation in metazoans and fission yeast (Norbury and Nurse 1992; Nyberg et al. 2002), it was conceivable that stalled DNA replication may somehow bypass Chk1 and Chk2 to control Cdc2 activity through T14/ Y15 phosphorylation. The phosphorylation state of Cdc2 

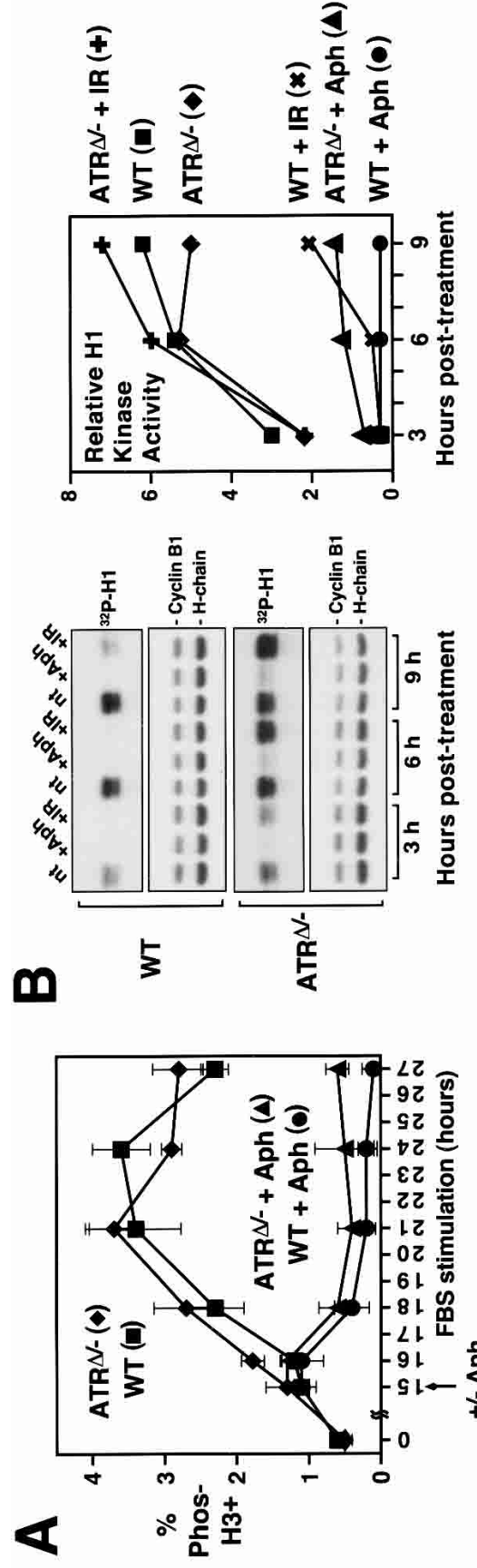
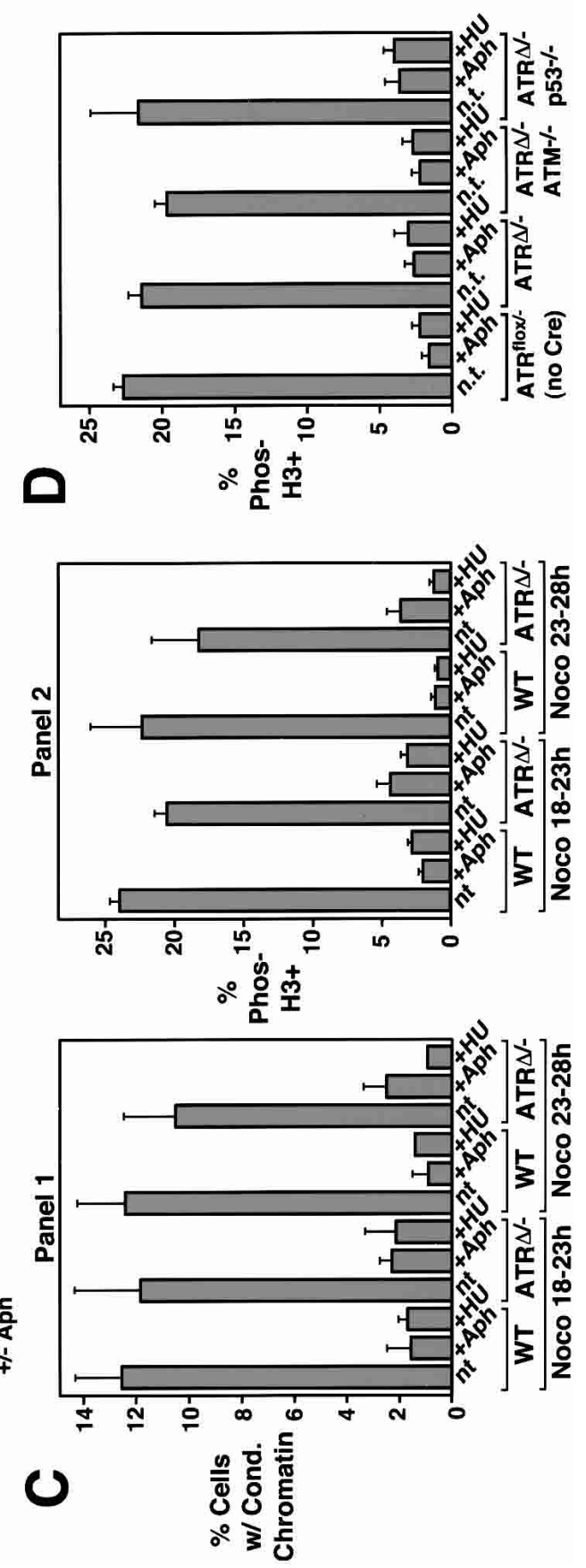

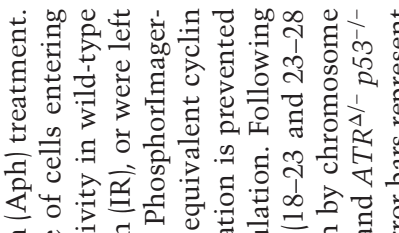

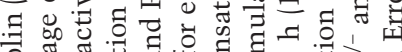

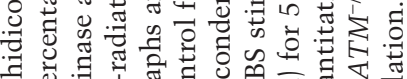

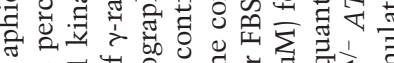

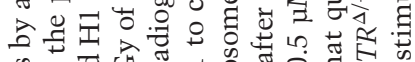

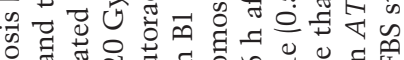

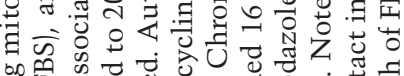

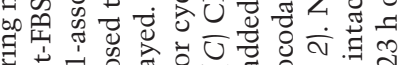
离市

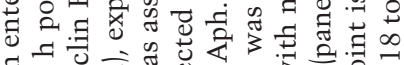

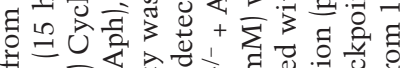

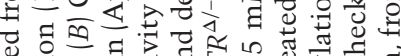

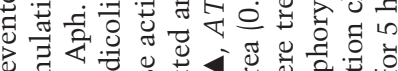

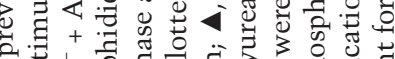

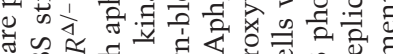

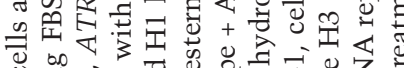
U ये

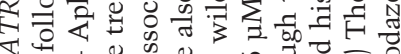

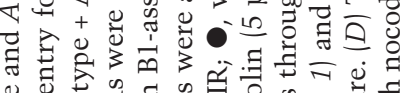

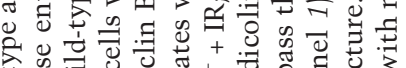

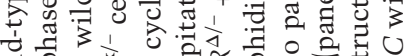

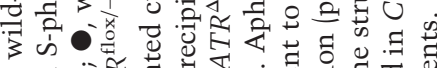

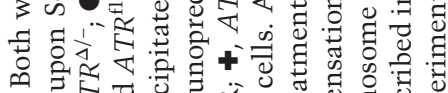

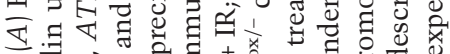

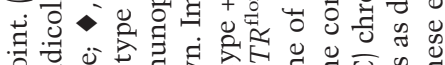

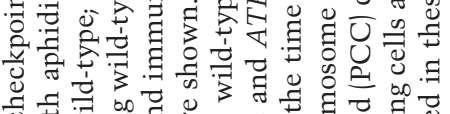

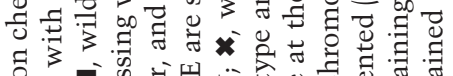

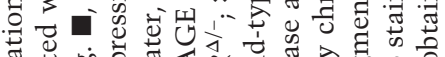

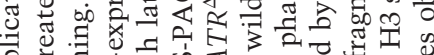

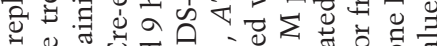

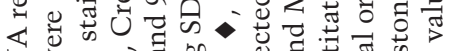

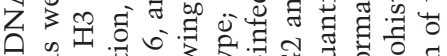
券击

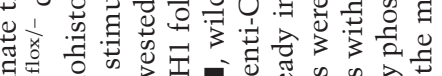

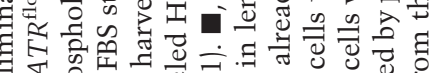
०

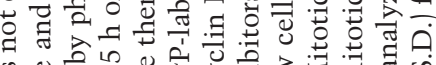
की

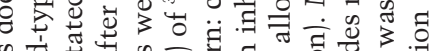

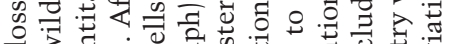

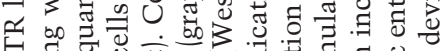

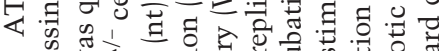

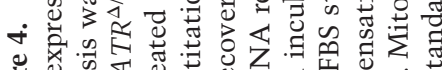

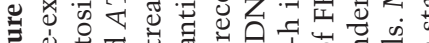

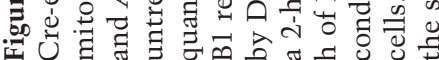


Figure 5. Regulation of Chk1 and Chk2 by ATR and ATM, respectively. (A) Chk1 phosphorylation in response to either aphidicolin or IR requires ATR. After $15 \mathrm{~h}$ of FBS stimulation, Cre-expressing wildtype and $A T R^{\text {flox/- }}$ MEFs were treated with aphidicolin or IR. Lysates were prepared at various times posttreatment, and Western blots were detected for phospho-S345 Chk1 (upper panel) or total Chk1 (lower panel). (B) Chk2 phosphorylation in response to aphidicolin and IR is not dependent on ATR. Samples generated as in $A$ were Western-blotted and detected for Chk2. The slower-migrating phosphorylated and faster-migrating unphosphorylated forms are indicated.
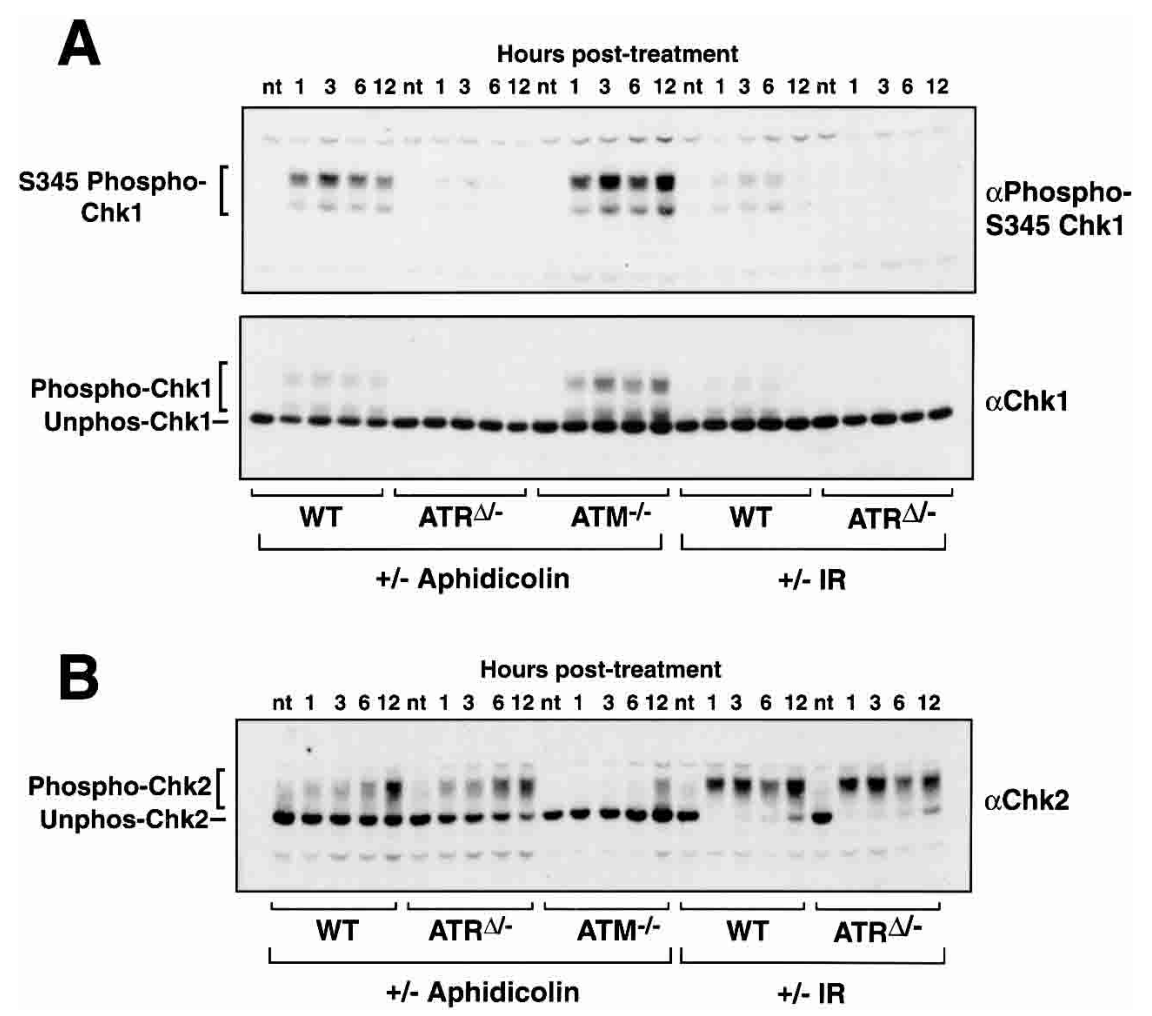

on T14 and Y15 was therefore assessed in aphidicolintreated wild-type and $A T R^{\Delta /-}$ cells and compared with that of IR-treated cells.

Cdc2 is initially phosphorylated in $S$ phase by the Weel and Myt1 kinases (Norbury and Nurse 1992; Nyberg et al. 2002). This phosphorylation is maintained until the early stages of mitosis, at which time these phosphates are removed by changes in the rates of phosphorylation and dephosphorylation. As indicated by slowed electrophoretic mobility, the well-characterized phosphorylation of Cdc2 was observed in both $A T R^{\Delta /-}$ and control cells upon serum-stimulated entry into S and G2 phase $18 \mathrm{~h}$ after FBS stimulation (Fig. 6A). Therefore, ATR is not required for the initial phosphorylation of Cdc2 that occurs upon S-phase entry. To examine the ability of DNA damage or stalled replication to maintain Cdc2 phosphorylation, wild-type and $A T R^{\Delta /-}$ cells were treated with aphidicolin or IR for 9 and $12 \mathrm{~h}$, and the accumulation of the T14/Y15-phosphorylated form of Cdc2 was assessed by Western blot (Fig. 6B). In wild-type cells, this accumulation occurred as expected over the course of treatment. In $A T R^{\Delta /-}$ cells, however, increased phosphorylation of $\mathrm{Cdc} 2$ was not observed following treatment with either aphidicolin or IR (Fig. 6B). Together these data indicate that both IR- and aphidicolininduced checkpoints use ATR for signaling events that ultimately lead to inhibitory phosphorylation of Cdc2; however, an additional mechanism to prevent cell cycle progression must be at work when DNA replication is incomplete.
ATR prevents generation of double-strand breaks in the event of stalled DNA replication

Recent studies in yeast have suggested that ATR may play a role in stabilizing stalled DNA replication forks. For example, stalled replication in Rad53 mutants, a conventional protein kinase that lies downstream of the ATR ortholog in S. cerevisiae Mec1, results in replication fork collapse and DSB formation (Lopes et al. 2001). More recently, Mecl has been shown to prevent generation of DSBs at slowly replicating regions of the genome (Cha and Kleckner 2002). These results have suggested a role for Mec1-dependent checkpoint signaling to stabilize stalled replication forks and prevent the generation of DSBs (Carr 2002). We therefore reasoned that generation of such breaks in aphidicolin-treated ATR knockout cells may play a role in preventing cell cycle progression in a manner that is independent of ATR's cell cycleinhibitory functions.

To test if ATR is required to prevent generation of DSBs in the event of stalled DNA replication, we first used H2AX phosphorylation as a marker of DSB formation in wild-type and $A T R^{\Delta /-}$ MEFs. H2AX is phosphorylated on serine 139 in response to IR-induced DSBs and in the course of VDJ recombination (Rogakou et al. 1998; Chen et al. 2000). Other forms of DNA damage cause only mild phosphorylation of H2AX (Burma et al. 2001), indicating that phosphorylation may be DSB-specific. Finally, recent studies indicate that phosphorylation of $\mathrm{H} 2 \mathrm{AX}$ is predominantly regulated by DNA-PK and ATM 


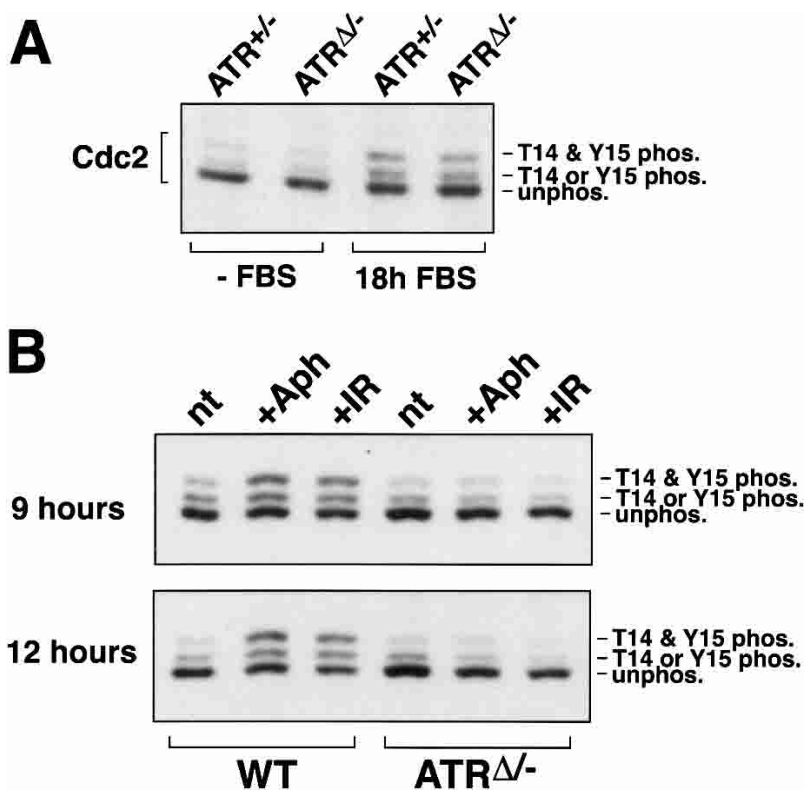

Figure 6. Cdc2 phosphorylation on T14 and Y15. (A) Cdc2 is phosphorylated normally as cells enter S phase. After $18 \mathrm{~h}$ of FBS stimulation, lysates from lenti-Cre-infected $A T R^{\text {flox/- }}$ cells were generated and subjected to SDS-PAGE and Western blot detection of Cdc2. The unphosphorylated (fastest-migrating), singly phosphorylated (phospho-T14 or phospho-Y15), and doubly phosphorylated (slowest-migrating, phospho-T14 and phospho-Y15) forms of Cdc2 are indicated. (B) Accumulation of phospho-T14/Y15 Cde2 following aphidicolin or IR does not occur in $A T R^{\Delta /-}$ cells. After $15 \mathrm{~h}$ of FBS stimulation, Cre-expressing wild-type and $A T R^{\text {flox/- }}$ cells were either left untreated (nt) or treated with either aphidicolin (Aph) or 20 Gy of $\gamma$-radiation (IR). Cells were then harvested 9 and $12 \mathrm{~h}$ after treatment, and lysates were Western-blotted and detected for Cdc2 as in $A$.

(Paull et al. 2000; Burma et al. 2001), and consistent with this analysis we have seen no effect of ATR loss on $\mathrm{H} 2 \mathrm{AX}$ phosphorylation in response to IR (data not shown). Therefore, if DSBs are generated in $A T R^{\Delta /-}$ upon stalled DNA replication, then aphidicolin treatment should cause a strong increase in $\mathrm{H} 2 \mathrm{AX}$ phosphorylation specifically in ATR knockout cells and little increase in wild-type cells. To assay for increased H2AX phosphorylation, lysates were prepared from wild-type and $A T R^{\Delta /-}$ cells that were treated or left untreated with aphidicolin for various times. Western blots of these lysates were then incubated with phospho-specific $\mathrm{H} 2 \mathrm{AX}$ antibodies. As shown in Figure 7A, little increase in H2AX phosphorylation occurred in wild-type cells upon aphidicolin treatment, consistent with previous studies (Burma et al. 2001). In contrast, a robust increase in H2AX phosphorylation was observed in $A T R^{\Delta /-}$ cells after $1 \mathrm{~h}$ of aphidicolin treatment and beyond (Fig. 7A). These experiments support a model in which ATR is required to prevent the formation of DSBs upon stalled DNA replication.

If breaks were induced by stalled DNA replication specifically in ATR-depleted cells, then it was conceivable that these breaks might somehow prevent mitotic entry in an ATR/ATM-independent manner. To test this pos- sibility and to further analyze ATR's involvement in preventing the appearance of DSBs, a chromosome spreadbased assay was developed. In this assay (Fig. 7B), shortterm treatment with aphidicolin was used to cause replication fork stalling, but this treatment was followed by removal of aphidicolin to allow cells to proceed into mitosis. Then, $2.5 \mathrm{~h}$ after removal of aphidicolin, $A T R^{\Delta /-}$ and control cells began to enter and accumulate in mitosis over the course of a 1.5-h nocodazole pile-up assay. Both mitotic spread quantitation (Fig. 7C) and phosphohistone $\mathrm{H} 3$ assays (data not shown) indicated that upon aphidicolin release, $A T R^{\Delta /-}$ cells were only slightly inhibited from entering mitosis in comparison with control cells. Importantly, these results indicate that aphidicolin-treated $A T R^{\Delta /-}$ cells have the ability to enter mitosis once inhibition of DNA replication is alleviated.

Mitotic spreads prepared from cells treated as above (Fig. 7C) were then analyzed for the percentage of mitotic cells exhibiting DSBs. The degree of chromosome breakage was categorized into three groups: normal (N), 1-10 breaks, and $>10$ breaks per mitotic spread (Fig. 7D). Few wild-type mitotic spreads had chromosome breaks either with or without aphidicolin treatment (Fig. 7E). A similar lack of aphidicolin-induced chromosome breaks was observed in $A T M^{-/-}$cells (data not shown). In contrast, $\sim 40 \%$ of $A T R^{\Delta /-}$ mitotic cells exhibited some form of chromosome breakage even in the absence of aphidicolin treatment, most with < 10 chromatid breaks per cell. These results are consistent with the chromosome breakage observed in previous ATR knockout studies (Brown and Baltimore 2000). However, when ATR-depleted cells were treated with aphidicolin for $2 \mathrm{~h}$ and then released into mitosis, an increase both in the degree of breakage per cell and in the percentage of cells exhibiting breaks was observed (Fig. 7E). The most dramatic difference was an increase in spreads exhibiting an extreme form of breakage, such as that shown in Figure 7D (>10 breaks). Because no differences in Annexin V staining were observed between wild-type and ATR knockout cells, either treated or left untreated with aphidicolin (Fig. 7F), the chromosome breakage apparent in aphidicolin-treated $A T R^{\Delta /-}$ cells is unlikely to be the result of an apoptotic program. Thus, $A T R^{\Delta /-}$ cells can enter mitosis after aphidicolin release (Fig. 7C) and do so despite the presence of extensive chromosome breakage (Fig. 7E).

These experiments demonstrate that although ATR is required for genome stability in the absence of exogenous treatment, it is particularly required in the event of stalled DNA replication. Moreover, the DSBs generated in aphidicolin-treated $A T R^{\Delta /-}$ cells themselves do not prevent mitotic entry because entry with breaks is observed once DNA replication is allowed to proceed (Fig. 7C). The ability of aphidicolin-released $A T R^{\Delta /-}$ cells to proceed into mitosis with breaks is consistent with the IR checkpoint studies described here, because IR also generates DSBs and $A T R^{\Delta /-}$ cells continue to enter mitosis despite IR treatment. The implications of these results for our understanding of checkpoint control and for ATR's cell cycle regulatory and genome maintenance functions are discussed below. 
Brown and Baltimore

A

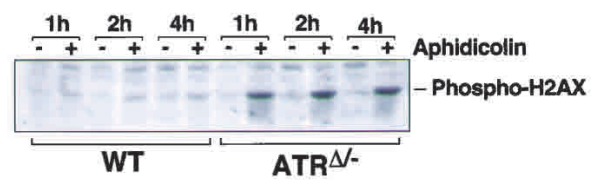

B

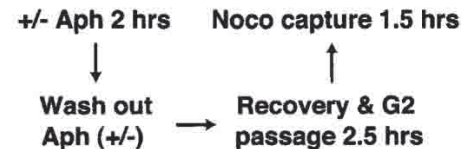

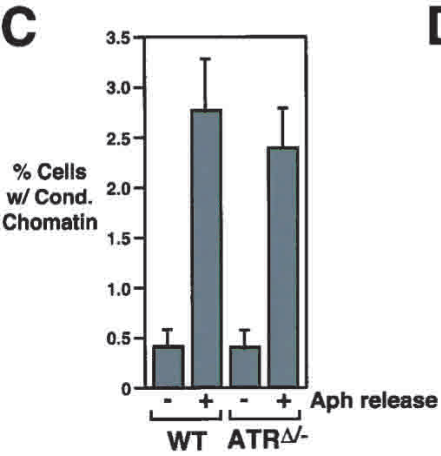

E

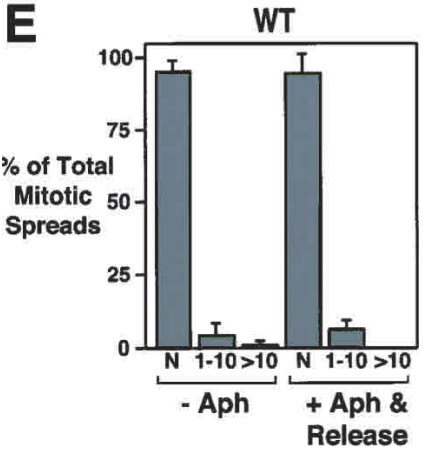

D

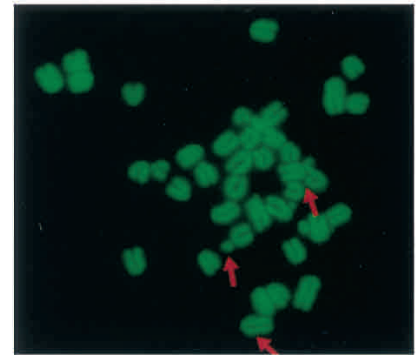

1-10 Chromosome

Breaks

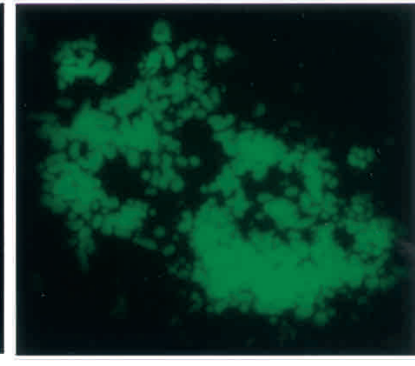

$>10$ Chromosome Breaks
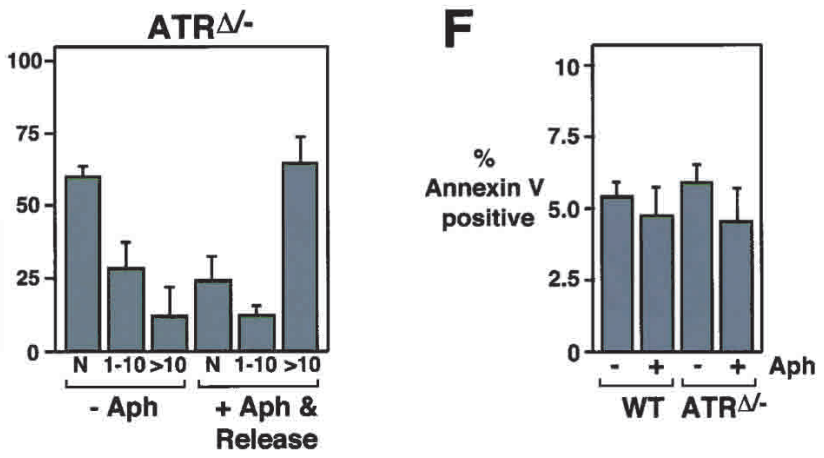

Figure 7. Aphidicolin causes DSBs in ATR-depleted cells, but DSBs do not prevent mitotic entry upon aphidicolin release. $(A)$ Aphidicolin causes phosphorylation of $\mathrm{H} 2 \mathrm{AX}$ in $A T R^{\Delta /-}$ cells. At $15 \mathrm{~h}$ of FBS stimulation, lenti-Cre-infected wild-type and $A T R^{\text {flox }}$ cells were left untreated or treated with aphidicolin. Cells were harvested 1, 2, and $4 \mathrm{~h}$ later. Lysates were Western-blotted and detected for phosphohistone H2AX. $(B)$ Schematic representation of an assay to quantitate the effect of DSBs on preventing mitotic entry and detect increased chromosome breakage upon aphidicolin treatment. (C) Mitotic entry of aphidicolin-treated wild-type and $A T R^{\Delta /-}$ cells after aphidicolin release. After a 2-h aphidicolin treatment, Cre-expressing wild-type and $A T R^{\text {flox } /-}$ MEFs were washed four times with $10 \%$ FBS DMEM to remove aphidicolin. Two and a half hours later, cells were collected in mitosis by nocodazole treatment $(0.5 \mu M)$ for $1.5 \mathrm{~h}$. Chromosome spreads were prepared to quantitate the percentage of cells entering mitosis and to assess chromosome breakage as described in $D$ and $E$ below. Cells were released from or maintained in aphidicolin as indicated. $(D)$ Mitotic spreads with differing degrees of chromosome breakage were observed and quantitated using the assay described in $B$ and $C$. Examples of spreads with $1-10$ breaks and $>10$ breaks are shown. (E) Aphidicolin induces breaks specifically in $A T R^{\Delta /-}$ cells. Cre-expressing wild-type and $A T R^{\text {flox/- }}$ MEFs released from aphidicolin treatment as described in $B$ and $C$ (+Aph \& Release) were analyzed for the frequency of each category of mitotic chromosome spread shown in $D$. The chromosome breakage observed in cells left untreated with aphidicolin is also shown (-Aph). N, normal chromosome spread. (F) Aphidicolin treatment does not cause apoptosis in $A T R^{\Delta /-}$ cells. Cre-expressing wild-type and $A T R^{\text {flox/- }}$ MEFs left untreated, treated with aphidicolin, or treated with and released from aphidicolin were stained for Annexin $\mathrm{V}$ and quantitated by flow cytometry.

\section{Discussion}

Using a Cre/lox-conditional system to study the effect of ATR loss, we have shown that ATR is an important regulator of checkpoint signaling pathways that are induced by IR and stalled DNA replication and lead to inhibitory phosphorylation of Cdc2. Despite this similarity, IR and stalled replication cause cell cycle delay in ways that differ in their requirements for this ATR-dependent pathway. Whereas loss of ATR eliminates IR- induced cell cycle delay, it has little effect on the delay induced by stalled DNA replication. It is clear that ATR regulates important arms of both the IR and DNA replication checkpoints through Cdc2 phosphorylation; however, these data also indicate that stalled DNA replication can prevent mitotic entry in an ATR-independent manner as well. These data are consistent with the existence of multiple independent mechanisms to prevent premature mitotic entry when DNA replication remains incomplete. 
ATR and ATM involvement in IR-induced cell cycle delay

Our studies demonstrate that ATR and ATM cooperate in preventing mitotic entry in response to IR. This response involves a complex network of checkpoint signaling molecules with differing requirements for ATR and ATM. For example, our results indicate that ATR is the chief regulator of Chk1 phosphorylation but has no involvement in Chk2 phosphorylation in response to either IR or stalled replication. Because Chk2 phosphorylation has been previously shown to mostly require ATM (Matsuoka et al. 1998), these results imply that there is little if any overlap in Chk1 and Chk2 regulation by ATR and ATM, respectively. In contrast, direct phosphorylation of p53 on serine 18 is codependent on ATR and ATM in a time-dependent manner (ATM involved in the early phase, ATR in the late). The importance of these differences in signaling partnerships and kinetic dependence remains unclear, but it may be related to the manner in which DSBs are initially sensed and later processed for repair as discussed below.

We have shown that ATR assists in the early phase of mitotic delay in response to IR and is particularly required for the late phase. In contrast, ATM appears to be more noticeably important for the early phase, as shown in previous studies (Xu et al. 2002). There are at least two conceivable models to explain the time-dependent requirements for ATR and ATM. One explanation is that the initial form of DNA breakage caused by IR is best recognized by ATM, whereas the repair intermediates that result from later processing of these initial breaks are better recognized by ATR. Thus, in this model ATR and ATM are specialized to elicit checkpoint responses to DSBs that are in various stages of processing, and until repair is complete these checkpoint responses remain active. Another model involves the cell cycle phase in which damage is sensed; for example, ATR may be particularly apt at sensing damage during DNA synthesis, but not afterwards in the G2 phase. Nevertheless, according to either model the differing activation of signaling pathways, such as Chk1 and Chk2, by ATR and ATM may reflect specific downstream cellular responses to distinct stages of DNA metabolism. Because ATR, ATM, Chk1, and Chk2 have been shown to differentially phosphorylate various genes involved in DNA repair, such as BRCA1, NBS1, Blm1, and others (Kastan and Lim 2000; Tibbetts et al. 2000; Zhou and Elledge 2000), it is tempting to speculate that downstream processes may include influencing the appropriate type of repair. The differing roles of ATR-Chk1 and ATM-Chk2 pathways in such a repair capacity, however, have not been formally tested.

\section{The DNA replication checkpoint}

We show that ATR regulates an important arm of the DNA replication checkpoint as indicated by ATR's requirement for activating phosphorylation of Chk1 and inhibitory phosphorylation of Cdc2 on T14/Y15. Based on decades of research on $\mathrm{Cdc} 2$ regulation, there is little doubt that phosphorylation of Cdc2 on T14/Y15 can be an important part of cell cycle checkpoint regulation (Norbury and Nurse 1992; Weinert 1997; Nyberg et al. 2002). However, given that cell cycle delay still occurs even in the absence of ATR, at least one additional mechanism to prevent premature mitotic entry must be at work in MEFs. It is formally possible that this additional mechanism may function using levels of ATR protein that are far below those required for regulation of Cdc2 T14/Y15 phosphorylation; however, there is no evidence at the present time to assume this is the case. The simplest explanation of our data is that the Cdc2 T14/15-independent mechanism is also independent of ATR. The ATR-independent mechanism of inhibition is not the result of a general loss of cellular function because $A T R^{\Delta /-}$ cells remain capable of entering mitosis once DNA replication inhibitors have been removed. Therefore, some aspect of inhibited DNA replication itself must be responsible for the ATR-independent mitotic delay. It is important to point out that deletion of the ATR orthologs MEC1 and RAD3 in budding and fission yeast, respectively, eliminate the DNA replication checkpoint (Al-Khodairy and Carr 1992; Enoch et al. 1992; Weinert et al. 1994; Boddy et al. 1998; Nyberg et al. 2002). Thus, our results indicate that incompletely replicated DNA in mammalian cells prevents mitotic entry differently than in yeast.

Our studies indicate that Cdc2/cyclin B itself may be the target of the ATR-independent mechanism of inhibition. This interpretation is based on previous studies implying that histone $\mathrm{H} 3$ phosphorylation is downstream of Cdc2/cyclin B activation (De Souza et al. 2000) and on our studies showing that aphidicolin-treatment of $A T R^{\Delta /-}$ cells prevents activation of cyclin B1-associated kinase activity (Fig. 4B). There are many possible mechanisms by which Cdc2/cyclin B1 can be inhibited other than Cdc2 T14/Y15 phosphorylation (Weinert 1997). Along these lines, it is important to point out that a titratable inhibitor of Cdc2/cyclin B kinase activity that acts independently of Cdc2 T14/Y15 phosphorylation has been previously observed in aphidicolin-treated Xenopus extracts (Kumagai and Dunphy 1995). It is possible that an equivalent inhibitor is at work in mammalian cells, one that acts independently of ATR and prevents $\mathrm{Cdc} 2 /$ cyclin $\mathrm{B}$ activation when DNA replication is left incomplete.

\section{ATR prevents the appearance of DSBs upon stalled DNA replication}

Previous work in yeast has indicated important roles for the ATR ortholog Mec1 and Mec1-dependent signaling pathways $(\operatorname{Rad} 53)$ in preventing DSB upon slowing or stalled DNA replication (Lopes et al. 2001; Cha and Kleckner 2002). The studies described herein confirm an important role for ATR in preventing DSBs during stalled DNA replication in mammalian cells. Because ATR also regulates cell cycle checkpoint signaling pathways, such as Chk1 phosphorylation and Cdc2 inhibition, our studies indicate that ATR affects both cell cycle 
regulation and genome maintenance in the event of stalled replication. It is interesting to note that, as a mammalian ortholog of Rad53, Chk1 may be the common regulator of both the checkpoint and genome maintenance functions downstream of ATR. Chk1 knockout mice die early in development, similar to ATR knockout mice (Liu et al. 2000). Although it is not known whether Chk1 knockout cells exhibit a form of genomic instability similar to that observed in ATR knockouts (Brown and Baltimore 2000), dominant-negative Chk1 overexpression has been reported to affect genome stability (Nghiem et al. 2001). The mechanism by which ATR, and possibly Chk1, maintains stability upon stalled replication is unknown but might involve the correct processing of regressed replication forks (Carr 2002) or stabilization of stalled forks by translesion bypass (Kai and Wang 2003), a process that is not inhibited by aphidicolin.

\section{Processive PIK-related kinase activation?}

Our data suggest a model in which ATR, ATM, and DNA-PK act in multiple layers to preserve genomic integrity. For example, we show that ATR is important to prevent DSB formation in the event of stalled DNA replication and that $\mathrm{H} 2 \mathrm{AX}$ is phosphorylated when these breaks form in ATR's absence (Fig. 7A). H2AX has previously been shown to be phosphorylated by ATM and DNA-PK at the sites of DSB formation (Rogakou et al. 1999; Burma et al. 2001). Thus, if ATR is unavailable to prevent DSB formation in the event of stalled replication, then these breaks are likely sensed by DNA-PK and/or ATM, which then go on to phosphorylate H2AX. It is interesting to point out that $\mathrm{H} 2 \mathrm{AX}$ has recently been shown to be required for efficient homologous recombination (Celeste et al. 2002); therefore, it is possible that phosphorylation of H2AX may be part of a process to repair these breaks or reinitiate replication fork progression (Cox et al. 2000). Although purely speculative at this time, our studies are consistent with the possibility that the multiple pathways in checkpoint regulation not only respond differently to the initial forms of DNA damage, but may also act in layers of activation that processively safeguard genomic integrity should an upstream system fail.

\section{Materials and methods}

Generation of mice with a lox-conditional allele of ATR and MEFs preparation

D3 ES cells were transfected with the targeting vector shown (Fig. 1A), selected in neomycin, and cloned as described (Brown and Baltimore 2000). To remove the neomycin cassette, pCAGGS-FLPe (Buchholz et al. 1998) was transfected into recombined ES cells, and these cells were transiently selected in puromycin $(2 \mu \mathrm{g} / \mathrm{mL})$ for $2 \mathrm{~d}$, expanded for $5 \mathrm{~d}$, and then selected in gancylovir $(1.5 \mu \mathrm{M})$ for $4 \mathrm{~d}$. ES cell clone DNA was analyzed by Southern blot as described (Brown and Baltimore 2000). To produce $A T R^{\text {flox/- }}$ and control MEFs, $A T R^{+/-}$(Brown and Balti- more 2000) and $A T R^{\text {flox } /+}$ mice were mated and E14.5 embryos were isolated. MEFs prepared from these embryos were grown in $10 \%$ FBS DMEM, genotyped, and infected with lenti-Cre virus within 2 or 3 doublings after isolation, as described below. $A T R^{\text {flox } /-} A T M^{-/-}$and $A T R^{\text {flox } /-}$ p53-/- MEFs were isolated similarly using the following parental crosses: $A T R^{\text {flox/flox }}$

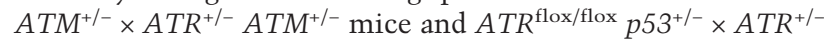
$p 53^{+/-}$mice. These parental genotypes were produced by breeding $A T R^{\text {flox } /+}$ and $A T R^{+/-}$(Brown and Baltimore 2000) mice with $A T M^{+-}$(Xu and Baltimore 1996) and $p 53^{+/-}$(Jacks et al. 1994) mice; progeny were subsequently intercrossed.

\section{Lenti-Cre constructs and infection of MEFs}

Cre-expressing lentiviruses were produced using retroviral expression vectors (Lois et al. 2002) and a packaging system previously described (Dull et al. 1998). Concentrated lenti-Cre preparations were titered using a lox-recombination reporter cell line [NIH3T3-lox-Lac Z, provided by Carlos Lois (Massachusetts Institute of Techology, Cambridge, MA) and Dan Van Antwerp (California Institute of Technology, Pasadena, CA)]. To recombine the $A T R^{\text {flox }}$ allele, MEFs were trypsinized and resuspended at $1 \times 10^{6}$ cells $/ \mathrm{mL}$ in $0.5 \%$ FBS DMEM and replated in the same media containing concentrated lenti-Cre virus $\left(1-3 \times 10^{8} \mathrm{TU} / \mathrm{mL}\right)$ at a multiplicity of infection (m.o.i.) of 5-10. This m.o.i. consistently resulted in expression of Cre in $>90 \%$ of the cells, as expected by Poisson distribution. At $18-24$ $\mathrm{h}$ after the start of infection, virus-containing media was removed and fresh $0.5 \%$ FBS DMEM was applied. The studies described herein were replicated using two forms of Cre recombinase, NLS-Cre (provided by J. Jacob, Emery University) and Cre-ERT2 (Feil et al. 1997), both of which recombined the $A T R^{\text {flox }}$ allele with similar efficiency and produced similar results.

Propidium iodide, phosphohistone H3, and Annexin $V$ staining

MEFs were tyrpsinized, washed in PBS, stained as described below, and analyzed using a Becton Dickinson FACScan flow cytometer (488 nm excitation laser). For propidium iodide staining, cells were resuspended in a solution containing $50 \mu \mathrm{g} / \mathrm{mL}$ propidium iodide, $0.1 \%$ Triton X-100, $50 \mu \mathrm{g} / \mathrm{mL}$ RNAse A, and $5 \mathrm{mM}$ EDTA at room temperature for $1 \mathrm{~h}$. This solution was then diluted 1:1 in 2\% FBS PBS for cytometric analysis. For Annexin V staining, PBS-washed cells were resuspended in 2\% FBS PBS containing $1 \mathrm{mM} \mathrm{CaCl}$ and a 1:100 dilution of Annexin V-PE (BD Pharmingen), incubated on ice for 15-30 min, and analyzed for PE emission by flow cytometry. Phosphohistone $\mathrm{H} 3$ staining was performed by a procedure similar to that previously described (Xu et al. 2002). Briefly, cells were fixed in ice cold $70 \%$ ethanol for $1 \mathrm{~h}$, followed by fixation in ice cold $95 \%$ ethanol $/ 5 \%$ acetic acid for $5 \mathrm{~min}$. Cells were washed twice with PBS and then permeabilized in $1 \%$ FBS/0.1\% Triton X-100 PBS (FTP) for $30 \mathrm{~min}$, followed by staining in $2 \mu \mathrm{g} / \mathrm{mL}$ antiphosphohistone $\mathrm{H} 3$ antibody (Upstate Biotechnology) in FTP at room temperature (RT) for $1.5 \mathrm{~h}$. Cells were then washed twice in FTP and incubated with FITC-conjugated anti-rabbit $\mathrm{F}\left(\mathrm{ab}^{\prime}\right)_{2}$ antibody (Jackson ImmunoResearch) in FTP at RT for $1.5 \mathrm{~h}$. After two additional washes in FTP, phosphohistone H3-positive cells were quantitated by flow cytometric detection of FITC emission.

\section{Mitotic spread preparation and quantitation}

Mitotic spreads were prepared from MEFs by methods described previously (Brown and Baltimore 2000). Slides of chromosome 
spreads were stained and mounted in SYBR green (Molecular Probes) diluted $1: 10,000$ in $85 \%$ glycerol $/ 15 \%$ PBS at $\mathrm{pH} 7.9$. To determine the percentage of cells in mitosis, the total number of mitotic spreads (normal + fragmented) were counted and divided by the total number of cells (interphase + mitotic). For measuring mitotic entry, $>500$ cells were counted for each replicate. Classification of chromosome fragmentation state (Fig. $7 \mathrm{E}$ ) was performed by analyzing $>50$ mitotic spreads for each of four experiments per condition.

\section{Cyclin B1-associated H1 kinase assays}

Cells were washed with $4^{\circ} \mathrm{C}$ PBS and then lysed at $4^{\circ} \mathrm{C}$ in $1 \mathrm{~mL}$ of PIP buffer (Brown et al. 1994) containing $150 \mathrm{mM} \mathrm{NaCl}$ and no DTT for $30 \mathrm{~min}$. Lysates were then clarified by centrifugation, and $1 \mu \mathrm{g}$ of anti-Cyclin B1 monoclonal antibody (CB-169, Upstate Biotechnology) was added to supernatants. After $2 \mathrm{~h}$ of gentle agitation, $5 \mu \mathrm{L}$ of (packed) protein $\mathrm{A} / \mathrm{G}$ beads (Oncogene Sciences) was added and incubated with extract for an additional $45 \mathrm{~min}$. Beads were then washed four times with lysis buffer and once with kinase reaction buffer $(50 \mathrm{mM}$ HEPES at $\mathrm{pH} 7.5,10 \mathrm{mM} \mathrm{MgCl}_{2}, 50 \mathrm{mM}$ 2-glycerophosphate, $0.1 \%$ Triton $\mathrm{X}-100$, and $1 \mathrm{mM}$ DTT). Kinase reactions were initiated by the addition of $30 \mu \mathrm{L}$ of kinase reaction buffer containing $5 \mu \mathrm{g}$ of histone $\mathrm{H} 1$ (Roche) and $50 \mu \mathrm{M}^{32} \mathrm{P}-\gamma$-ATP $(1.67 \mathrm{Ci} / \mathrm{mmole})$ and incubated at $37^{\circ} \mathrm{C}$ for $10 \mathrm{~min}$. Reactions were stopped by addition of $40 \mu \mathrm{L}$ of $2 \times$ Laemmli sample buffer and boiling for $5 \mathrm{~min}$. Phosphorylation of $\mathrm{H} 1$ was quantitated following SDS-PAGE by autoradiography (Fig. 4B) and by a Molecular Dynamics Storm 860 PhosphorImager (Fig. 4B, graph).

\section{Antibodies and Western blot detection}

Whole-cell extracts were prepared by lysing cells in Laemmli sample buffer, separating proteins by SDS-PAGE, and blotting to either nitrocellulose or PVDF membranes (Immobilon P, Millipore). Blots were blocked in TBST containing 5\% nonfat dried milk (NFDM) and incubated at RT for $1-2 \mathrm{~h}$ with primary antibodies as follows: ATR was detected with anti-human ATR (2381-2644) antibodies (Serotec) diluted in 1:5000 dilution in $5 \%$ NFDM TBST. Chk1 was detected with monoclonal antibodies to full-length Chk1 (sc-8408, Santa Cruz Biotechnology) diluted in 5\% NFDM TBST and incubated with blots at RT for 1 h. Phosphoserine 18 of mouse p53 and phosphoserine 345 Chk1 were detected by incubation with commercially available antibodies (\#9284 and \#2341, Cell Signaling Technology) at RT for $1 \mathrm{~h} \mathrm{(P-S18} \mathrm{p53)} \mathrm{or} \mathrm{at} 4^{\circ} \mathrm{C}$ for $>16 \mathrm{~h}$ (P-S345 Chk1), diluted 1:1000 in 5\% BSA TBST. Anti-Chk2 polyclonal antibodies [gift of Steve Elledge (Baylor College, Houston, TX); Matsuoka et al. 1998] were used at a 1:500 dilution in 5\% BSA at RT for $2 \mathrm{~h}$. $\mathrm{Cdc} 2$ and cyclin $\mathrm{B} 1$ were detected with $1 \mu \mathrm{g} / \mathrm{mL}$ dilutions of anti-Cdc2 (Ab-3, Calbiochem) and anti-cyclin B1 (GNS-1, BD Pharmingen) monoclonal antibodies in TBST. Finally, antiphosphoserine $139 \mathrm{H} 2 \mathrm{AX}$ antibodies (Upstate Biotechnology) were used at a 1:1000 dilution in 3\% NFDM TBST incubated with blots at $4^{\circ} \mathrm{C}$ for $6 \mathrm{~h}$.

\section{Acknowledgments}

We especially thank Carlos Lois for assistance and training in lentivirus preparation, Shirley Pease for blastocyst injections, and Karlene Cimprich for critically reading the manuscript. We are also indebted to John Petrini, Steve Elledge, Chris Canman, and Joel Pomerantz for helpful advice; to Paul Nghiem and Thomas Glover for sharing unpublished results; and to Lilia
Anonuevo, Shannon Witherow, and Bruce Kennedy for assistance in mouse care. Finally, we thank Steve Elledge, Francis Stewart, Didier Trono, Dan Van Antwerp, and Joshy Jacob for generously providing reagents. Funds for this research were provided by a grant from the NIH (2R01CA51462-14). E.J.B. was supported by a Breast Cancer Research Program postdoctoral fellowship.

The publication costs of this article were defrayed in part by payment of page charges. This article must therefore be hereby marked "advertisement" in accordance with 18 USC section 1734 solely to indicate this fact.

\section{References}

Al-Khodairy, F. and Carr, A.M. 1992. DNA repair mutants defining G2 checkpoint pathways in Schizosaccharomyces pombe. EMBO J. 11: 1343-1350.

Boddy, M.N., Furnari, B., Mondesert, O., and Russell, P. 1998. Replication checkpoint enforced by kinases Cds1 and Chk1. Science 280: 909-912.

Brown, E.J. and Baltimore, D. 2000. ATR disruption leads to chromosomal fragmentation and early embryonic lethality. Genes \& Dev. 14: 397-402.

Brown, E.J., Albers, M.W., Shin, T.B., Ichikawa, K., Keith, C.T., Lane, W.S., and Schreiber, S.L. 1994. A mammalian protein targeted by G1-arresting rapamycin-receptor complex. Nature 369: 756-758.

Buchholz, F., Angrand, P.O., and Stewart, A.F. 1998. Improved properties of FLP recombinase evolved by cycling mutagenesis. Nat. Biotechnol. 16: 657-662.

Burma, S., Chen, B.P., Murphy, M., Kurimasa, A., and Chen, D.J. 2001. ATM phosphorylates histone H2AX in response to DNA double-strand breaks. I. Biol. Chem. 276: 4246242467.

Carr, A.M. 2002. Checking that replication breakdown is not terminal. Science 297: 557-558.

Celeste, A., Petersen, S., Romanienko, P.J., Fernandez-Capetillo, O., Chen, H.T., Sedelnikova, O.A., Reina-San-Martin, B., Coppola, V., Meffre, E., Difilippantonio, M.J., et al. 2002. Genomic instability in mice lacking histone H2AX. Science 296: 922-927.

Cha, R.S. and Kleckner, N. 2002. ATR homolog Mecl promotes fork progression, thus averting breaks in replication slow zones. Science 297: 602-606.

Chao, C., Saito, S., Anderson, C.W., Appella, E., and Xu, Y. 2000. Phosphorylation of murine p53 at ser-18 regulates the p53 responses to DNA damage. Proc. Nat1. Acad. Sci. 97: 11936-11941.

Chen, H.T., Bhandoola, A., Difilippantonio, M.J., Zhu, J., Brown, M.J., Tai, X., Rogakou, E.P., Brotz, T.M., Bonner, W.M., Ried, T., et al. 2000. Response to RAG-mediated VDJ cleavage by NBS1 and $\gamma$-H2AX. Science 290: 1962-1965.

Cliby, W.A., Roberts, C.J., Cimprich, K.A., Stringer, C.M., Lamb, J.R., Schreiber, S.L., and Friend, S.H. 1998. Overexpression of a kinase-inactive ATR protein causes sensitivity to DNA-damaging agents and defects in cell cycle checkpoints. EMBO J. 17: 159-169.

Cortez, D., Guntuku, S., Qin, J., and Elledge, S.J. 2001. ATR and ATRIP: Partners in checkpoint signaling. Science 294: 17131716.

Cox, M.M., Goodman, M.F., Kreuzer, K.N., Sherratt, D.J., Sandler, S.J., and Marians, K.J. 2000. The importance of repairing stalled replication forks. Nature 404: 37-41.

De Souza, C.P., Osmani, A.H., Wu, L.P., Spotts, J.L., and Osmani, S.A. 2000. Mitotic histone H3 phosphorylation by the 
NIMA kinase in Aspergillus nidulans. Cell 102: 293-302.

Dull, T., Zufferey, R., Kelly, M., Mandel, R.J., Nguyen, M., Trono, D., and Naldini, L. 1998. A third-generation lentivirus vector with a conditional packaging system. I. Virol. 72: 8463-8471.

Enoch, T., Carr, A.M., and Nurse, P. 1992. Fission yeast genes involved in coupling mitosis to completion of DNA replication. Genes \& Dev. 6: 2035-2046.

Feil, R., Wagner, J., Metzger, D., and Chambon, P. 1997. Regulation of Cre recombinase activity by mutated estrogen receptor ligand-binding domains. Biochem. Biophys. Res. Commun. 237: 752-757.

Guo, Z., Kumagai, A., Wang, S.X., and Dunphy, W.G. 2000. Requirement for ATR in phosphorylation of Chk1 and cell cycle regulation in response to DNA replication blocks and UV-damaged DNA in Xenopus egg extracts. Genes \& Dev. 14: 2745-2756.

Hekmat-Nejad, M., You, Z., Yee, M., Newport, J.W., and Cimprich, K.A. 2000. Xenopus ATR is a replication-dependent chromatin-binding protein required for the DNA replication checkpoint. Curr. Biol. 10: 1565-1573.

Jacks, T., Remington, L., Williams, B.O., Schmitt, E.M., Halachmi, S., Bronson, R.T., and Weinberg, R.A. 1994. Tumor spectrum analysis in p53-mutant mice. Curr. Biol. 4: 1-7.

Kai, M. and Wang, T.S. 2003. Checkpoint activation regulates mutagenic translesion synthesis. Genes \& Dev. 17: 64-76.

Kastan, M.B. and Lim, D.S. 2000. The many substrates and functions of ATM. Nat. Rev. Mol. Cell. Biol. 1: 179-186.

Kumagai, A. and Dunphy, W.G. 1995. Control of the Cdc2/ cyclin B complex in Xenopus egg extracts arrested at a G2/M checkpoint with DNA synthesis inhibitors. Mol. Biol. Cell 6: 199-213.

Kumagai, A., Guo, Z., Emami, K.H., Wang, S.X., and Dunphy, W.G. 1998. The Xenopus Chk1 protein kinase mediates a caffeine-sensitive pathway of checkpoint control in cell-free extracts. J. Cell Biol. 142: 1559-1569.

Liu, Q., Guntuku, S., Cui, X.S., Matsuoka, S., Cortez, D., Tamai, K., Luo, G., Carattini-Rivera, S., DeMayo, F., Bradley, A., et al. 2000. Chk1 is an essential kinase that is regulated by ATR and required for the $\mathrm{G}_{2} / \mathrm{M}$ DNA damage checkpoint. Genes \& Dev. 14: 1448-1459.

Lois, C., Hong, E.J., Pease, S., Brown, E.J., and Baltimore, D. 2002. Germline transmission and tissue-specific expression of transgenes delivered by lentiviral vectors. Science 295: 868-872.

Lopes, M., Cotta-Ramusino, C., Pellicioli, A., Liberi, G., Plevani, P., Muzi-Falconi, M., Newlon, C.S., and Foiani, M. 2001. The DNA replication checkpoint response stabilizes stalled replication forks. Nature 412: 557-561.

Matsuoka, S., Huang, M., and Elledge, S.J. 1998. Linkage of ATM to cell cycle regulation by the Chk2 protein kinase. Science 282: 1893-1897.

Nghiem, P., Park, P.K., Kim, Y., Vaziri, C., and Schreiber, S.L. 2001. ATR inhibition selectively sensitizes G1 checkpointdeficient cells to lethal premature chromatin condensation. Proc. Natl. Acad. Sci. 98: 9092-9097.

Nghiem, P., Park, P.K., Kim, Y.S., Desai, B.N., and Schreiber, S.L. 2002. ATR is not required for p53 activation but synergizes with p53 in the replication checkpoint. J. Biol. Chem. 277: 4428-4434.

Norbury, C. and Nurse, P. 1992. Animal cell cycles and their control. Annu. Rev. Biochem. 61: 441-470.

Nyberg, K.A., Michelson, R.J., Putnam, C.W., and Weinert, T.A. 2002. Toward maintaining the genome: DNA damage and replication checkpoints. Annu. Rev. Genet. 36: 617-656.

Paull, T.T., Rogakou, E.P., Yamazaki, V., Kirchgessner, C.U.,
Gellert, M., and Bonner, W.M. 2000. A critical role for histone $\mathrm{H} 2 \mathrm{AX}$ in recruitment of repair factors to nuclear foci after DNA damage. Curr. Biol. 10: 886-895.

Rogakou, E.P., Pilch, D.R., Orr, A.H., Ivanova, V.S., and Bonner, W.M. 1998. DNA double-stranded breaks induce histone H2AX phosphorylation on serine 139. J. Biol. Chem. 273: 5858-5868.

Rogakou, E.P., Boon, C., Redon, C., and Bonner, W.M. 1999. Megabase chromatin domains involved in DNA doublestrand breaks in vivo. J. Cell Biol. 146: 905-916.

Sanchez, Y., Wong, C., Thoma, R.S., Richman, R., Wu, Z., Piwnica-Worms, H., and Elledge, S.J. 1997. Conservation of the Chk1 checkpoint pathway in mammals: Linkage of DNA damage to Cdk regulation through Cdc25. Science 277: 1497-1501; Comment, 277: 1450-1451.

Tibbetts, R.S., Brumbaugh, K.M., Williams, J.M., Sarkaria, J.N., Cliby, W.A., Shieh, S.Y., Taya, Y., Prives, C., and Abraham, R.T. 1999. A role for ATR in the DNA damage-induced phosphorylation of p53. Genes \& Dev. 13: 152-157.

Tibbetts, R.S., Cortez, D., Brumbaugh, K.M., Scully, R., Livingston, D., Elledge, S.J., and Abraham, R.T. 2000. Functional interactions between BRCA1 and the checkpoint kinase ATR during genotoxic stress. Genes \& Dev. 14: 2989-3002.

Weinert, T. 1997. A DNA damage checkpoint meets the cell cycle engine. Science 277: 1450-1451.

Weinert, T.A., Kiser, G.L., and Hartwell, L.H. 1994. Mitotic checkpoint genes in budding yeast and the dependence of mitosis on DNA replication and repair. Genes \& Dev. 8: 652-665.

Xu, B., Kim, S.T., Lim, D.S., and Kastan, M.B. 2002. Two molecularly distinct $\mathrm{G}_{2} / \mathrm{M}$ checkpoints are induced by ionizing irradiation. Mol. Cell. Biol. 22: 1049-1059.

$\mathrm{Xu}$, Y. and Baltimore, D. 1996. Dual roles of ATM in the cellular response to radiation and in cell growth control. Genes \& Dev. 10: 2401-2410.

Zhao, H. and Piwnica-Worms, H. 2001. ATR-mediated checkpoint pathways regulate phosphorylation and activation of human Chk1. Mol. Cell. Biol. 21: 4129-4139.

Zhou, B.B. and Elledge, S.J. 2000. The DNA damage response: Putting checkpoints in perspective. Nature 408: 433-439.

Zou, L., Cortez, D., and Elledge, S.J. 2002. Regulation of ATR substrate selection by Rad17-dependent loading of Rad9 complexes onto chromatin. Genes \& Dev. 16: 198-208. 


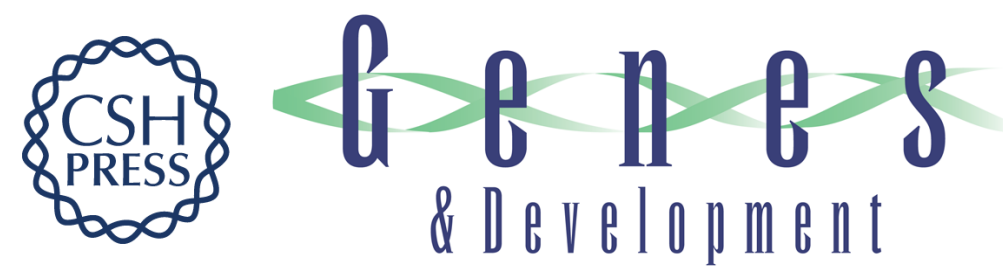

\section{Essential and dispensable roles of ATR in cell cycle arrest and genome maintenance}

Eric J. Brown and David Baltimore

Genes Dev. 2003, 17:

Access the most recent version at doi:10.1101/gad.1067403

References This article cites 46 articles, 32 of which can be accessed free at: http://genesdev.cshlp.org/content/17/5/615.full.htmI\#ref-list-1

License

Email Alerting Receive free email alerts when new articles cite this article - sign up in the box at the top Service right corner of the article or click here.

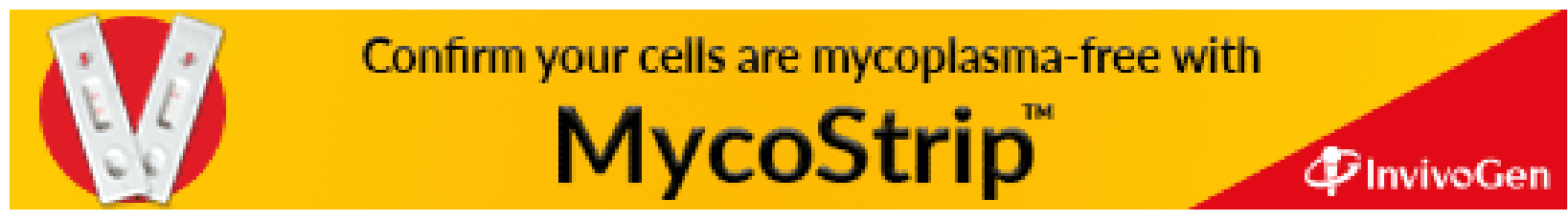

